\section{DIARY}

\section{MARCH}

UCL Eastman CPD: Thinking of Buying or Selling a Practice?

Date: 31 March 2011

Email:m.kelly@eastman.ucl.ac.uk

Telephone: 02079051234

\section{APRIL}

Oral-B Up To Date scientific

exchange seminar

Date: 7 April 2011

Venue: St David's Hotel, Cardiff

Email: julia@ab-communications.com

Telephone: 07585508550

BADT Professionalism in Practice workshop

Date: 9 April 2011

Email:a.mccann@leeds.ac.uk

www.badt.org.uk/events

BACD: Pink is the new white -

simple and predictable gingival

surgery for the general dentist

Date: 13 April 2011

Venue: Liverpool

Email: suzy@bacd.com

Telephone: 02082418526
Get the Right Angle on Digital

Imaging \& IRMER

Date: 13 April 2011

Venue: Leeds

Email: suzanne.o'rourke@henryschein.com

Telephone: 02920442818

2011 International

Osteology Symposium

Date: 14-16 April 2011

Venue: Cannes, France

Email: infouk@biohorizons.com

Telephone: 01344752560

www.biohorizons.com

iTOP: Developing proven strategies for more effective patient communication

Date: 15-16 April 2011

Venue: Shrigley Hall, Macclesfield

Email: info@curaprox.co.uk

www.curaprox.co.uk

BACD: The world of

CEREC CAD/CAM

Date: 21 April 2011

Venue: Belfast

Email: suzy@bacd.com

Telephone: 02082418526

\title{
COMMUNITIES ENCOURAGED TO HELP SMOKERS QUIT
}

Despite the circulation of a photograph of Kate Moss sashaying down a Paris catwalk, cigarette in hand, throughout the UK media, on this year's No Smoking Day, Health Secretary Andrew Lansley announced new ambitions to tackle the substantial public health harms from tobacco.

The Government has published Healthy lives, healthy people: a tobacco control plan for England which sets out how tobacco control will be delivered over the next five years.

Local communities will take a leading role in reducing smoking rates. The plan confirms action to end eye catching tobacco displays in shops which encourage young people to start smoking.

'Over eight million people in England still smoke and it causes more than 80,000 deaths each year,' said Mr Lansley. 'We want to do everything we can to help people to choose to stop smoking and encourage young people not to start in the first place. We will help local communities to take a comprehensive approach to reducing smoking so we can change social attitudes to smoking.'

By the end of 2015 the Government hopes to reduce smoking rates from $21.2 \%$ to $18.5 \%$ or less among adults.

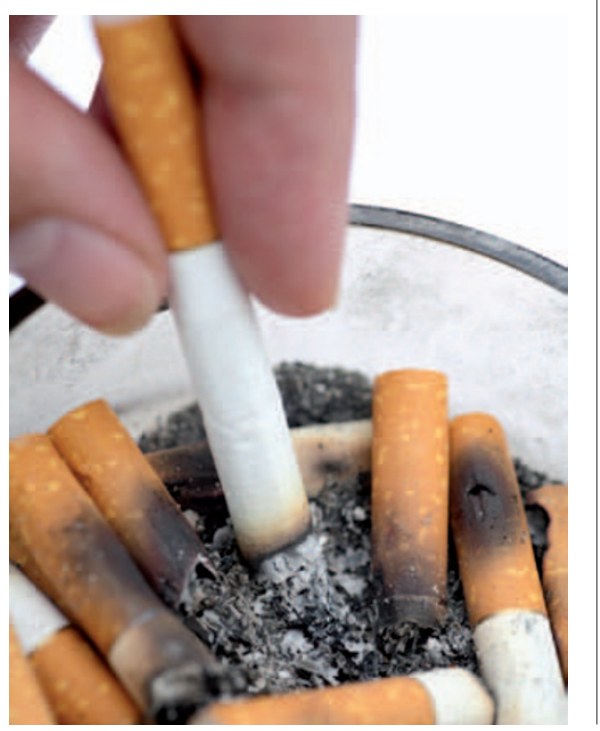

